\title{
SACRIFICIOS CANINOS EN LAS JÁNDICAS: UNA HIPÓTESIS SOBRE EL CULTO A ENODIA EN EL EJÉRCITO MACEDONIO ${ }^{1}$
}

\author{
DOG SACRIFICES IN THE XANDICA: A HYPOTHESIS ON \\ THE CULT OF ENNODIA IN THE MACEDONIAN ARMY
}

POR

Mario Agudo Villanueva*

\section{RESUMEN - ABSTRACT}

El descuartizamiento de una perra como ceremonia de purificación previa a un combate ritual que el ejército macedonio celebraba en las Jándicas podría tener relación con el culto a la diosa Enodia, una diosa equivalente a Hécate en el entorno cultural tesalio y macedonio. A partir de los testimonios de las fuentes históricas y de los restos arqueológicos, se trata de probar esta hipótesis, en la que se plantea la posibilidad de que este ritual fuera incorporado con los contingentes tesalios que Filipo II introdujo en el ejército macedonio en el contexto de la profunda reforma militar que implantó al llegar al poder.

The dismemberment of a female dog as a purification ceremony before a ritual combat that the Macedonian army held in the Xandica, could be related to Ennodia goddess, an equivalent to Hecate in the Thessalian and Macedonian context. From the historical sources statements and the archaeological remains, we try to prove this hypothesis, in which we present the possibility that this ritual was incorporated with Thessalian troops that Philip II introduced in the Macedonian army in the context of the deep military reform developed when he came to the head of the kingdom.

\section{Palabras Clave - Keywords}

Macedonia; Tesalia; Enodia; Filipo II; Alejandro Magno; Hécate; Feras.

Macedonia; Thessaly; Ennodia; Philip II; Alexander the Great; Hekate; Pherae.

\section{INTRODUCCIÓN}

En un pasaje de su Historia de Alejandro Magno, Quinto Curcio Rufo nos informa sobre una costumbre de "purificación" del ejército macedonio que se basaba en el sacrificio de una perra. Según el historiador romano, una vez muerto Alejandro, en el 323 a. C., en plena efervescencia de las disputas por el poder, Pérdicas y Meleagro, tras reconciliarse, deciden abordar este rito siguiendo "la costumbre macedonia" que, en palabras de nuestra fuente, se basaba en el siguiente ceremonial: "Mataban una perra y sus vísceras las arrojaban en las dos extremida-

1 Quiero agradecer a Antonio Ignacio Molina Marín su importante aportación a esta investigación, ayudándome a traducir algunos textos y proporcionándome otros de gran interés.

*Universidad Complutense de Madrid, marioagudo@gmail.com, http://orcid.org/0000-0003-3364-231X. 
des de una llanura; en medio era introducido todo el ejército armado, a un lado la caballería, al otro la falange" $\left(X, 9-12^{2}\right)$.

Ya en tiempos de Filipo V, en el contexto de las acusaciones de Perseo de Macedonia contra su hermano Demetrio por su supuesta amistad con la emergente Roma, hacia el año 180 a. C., es decir, casi dos siglos más tarde de los acontecimientos narrados por Curcio, Tito Livio nos ofrece un relato muy semejante al anterior, pero enriquecido con más detalles ${ }^{3}$. El historiador romano nos explica que:

Precisamente entonces llegó la fecha de la purificación del ejército, cuyo ceremonial consiste en lo siguiente: se corta una perra por la mitad y se coloca la parte de la cabeza en el lado derecho del lugar de paso, y la parte trasera, con las entrañas, en el lado izquierdo. Entre estas dos mitades de la víctima se hace desfilar a las tropas con sus armas. A la cabeza del desfile son portadas las armas y los emblemas de todos los reyes de Macedonia desde sus más remotos orígenes; sigue luego el rey con sus hijos, a continuación desfila la cohorte real y su guardia personal, y cierra la marcha el resto de las tropas de macedonios (XL 6. 1-34).

Un poco más adelante, el autor nos detalla que:

Finalizado el rito de la purificación era costumbre que el ejército realizara ejercicios repartiéndose en dos líneas de batalla que se enfrentaban en un simulacro de combate. Los jóvenes príncipes fueron designados como jefes para esta batalla simulada; pero no fue un combate fingido sino que cargaron como si el reino estuviera en juego (XL 6. 5-7).

El combate ritual era muy frecuente en la Antigüedad. Se trataba de una ceremonia que, de forma general, estaba destinada a conmemorar un episodio del drama cósmico o divino. Cada vez que el conflicto se repite, se reproduce un modelo arquetípico. En la medida en que los participantes en este rito se involucran en la acción, abandonan el tiempo profano de los mortales para trasladarse al mundo divino de los inmortales, pero uno no puede participar de la divinidad sin haber expiado previamente las impurezas que le unen al mundo terrenal ${ }^{5}$.

Esta es la secuencia que observamos en el ritual descrito por Curcio Rufo y Tito Livio. Los soldados macedonios purificaban su sangre mediante el descuartizamiento de una perra para participar en un combate ritual, dirigidos por la familia real, en el que se rememoraba algún acontecimiento mítico del pasado. Molina Marín ha vinculado de forma lúcida este rito con una de las estructuras de legitimación que desarrollaron los Argéadas para fortalecer la monarquía macedonia a través de la emulación de las dos gestas que sus antepasados Heracles y Zeus habían realizado en el territorio que ocupaba su reino de origen: la gigantomaquia y la tifonomaquia ${ }^{6}$.

\section{LAS JÁNDICAS}

Una glosa de Hesiquio, que recogemos a través de la traducción de Goukowsky, nos permite identificar este ritual en el contexto de la celebración de las Jándicas, que se oficiaban en

2 Traducción al castellano de Francisco Pejenaute Rubio para Gredos. Madrid, 1986.

3 A pesar de la distante cronología de los hechos relatados, Tito Livio y Quinto Curcio Rufo eran casi contemporáneos. Tito Livio vivió entre los años 59 a.C. y 17 d.C., mientras que la obra de Curcio Rufo se ha situado en el siglo I d.C., bien en época de Claudio, bien en época de Vespasiano. Este hecho podría ser interesante si consideráramos la descripción del ritual como un constructum, pero durante el estudio veremos que tiene importantes posibilidades de ser cierto.

4 Traducción al castellano de José Antonio Villar Vidal para Gredos. Madrid, 1990.

5 Hocart, 1935: 188 y 319. Eliade, 2008: 36-37 y 42-43. Chevalier y Gheerbrant, 2007: 657-658.

6 Molina Marín, 2014: 82-85. 
el mes de Xanthikos —el equivalente a nuestro abril—, justo en el equinoccio de primavera ${ }^{7}$, y se aprovechaban para purificar el ejército macedonio.

$\mathrm{Si}$ seguimos la tesis de Kalleris, por la que los nombres de los meses del calendario macedonio estarían derivados de festividades religiosas ${ }^{8}$, tendremos que asociar esta ceremonia con la figura de Janto.

Los testimonios que nos han llegado de esta celebración del ejército están relacionados con momentos de disputa, lo que plantea la posibilidad de que no siempre tuvieran una fecha fija en el calendario y se convocaran de forma excepcional por elección del rey, que podría utilizar la experiencia como catarsis para reducir las confrontaciones internas y reforzar la unidad ${ }^{9}$. En otra línea interpretativa, para algunos autores este festival constituía un rito de paso a través del cual los jóvenes reclutas se integraban entre los veteranos del ejército a través de una ceremonia en la que eran partícipes de un rito oficiado por su propio rey ${ }^{10}$.

Janto es una figura de origen incierto. Algunos autores la han asociado con Ares ${ }^{11}$, aunque esta tesis es difícil de conciliar con la etimología del término, que hace referencia a la claridad o luminosidad ${ }^{12}$. Ares es el dios de la guerra, que se goza en la matanza y en la sangre, pero los griegos trataron de mostrar su fuerza contenida o burlada por la más inteligente de Heracles o la de la astuta Atenea, por esta razón aparece muchas veces derrotado y con connotaciones peyorativas ${ }^{13}$.

Otra tesis nos presenta a Janto como el héroe que luchó contra Melanto en las fronteras entre Beocia y Ática, acontecimiento que algunos vinculan con la celebración de las Apaturias ${ }^{14}$. El significado de ambos apelativos se relaciona, en este contexto, con los términos rubio y moreno, es decir, luz y oscuridad, por lo que el hecho de que las Jándicas se celebren en primavera podría tener que ver con el triunfo de la luz sobre las tinieblas, hecho que Molina Marín vincula también a la Musomachia, pudiendo haber estado relacionados Tifón y los gigantes con la oscuridad y las musas y deidades olímpicas con la luz ${ }^{15}$.

En la línea de interpretación que considera el término Janto equivalente a rubio, Goukowsky lo vincula con Orfeo, quien según la tradición macedonia estaba enterrado en Dion, en honor de quien las mujeres tracias se decoloraban el pelo ${ }^{16}$. Muller, Kalleris y Chrysostomou lo relacionan con el apelativo xanthos atribuido a Apolo, como epíteto equivalente al de phoebus, brillante ${ }^{17}$. Apolo encarna también el triunfo del orden sobre el caos, en la medida en que aparece como el dios que vence a Pitón ${ }^{18}$, por lo que su rol encaja con la posibilidad de que ese combate ritual tuviera lugar para conmemorar esa gesta. Mientras que para Hatzopoulos el apelativo se referiría a Heracles ${ }^{19}$.

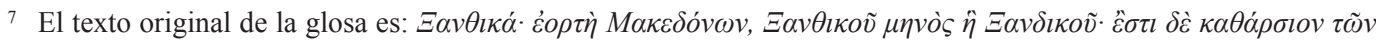
$\sigma \tau \rho \alpha \tau \varepsilon \mu \alpha \dot{\alpha} \tau \omega v$, que Goukowsky traduce por: "Xanthika: fête religieuse des Macédoniens, célébrée au mois de Xanthikos ou Xandikos. Il y a d'autre part une purification des forces armées". Goukowsky, 2009: 94-95. Más información sobre esta festividad en Kalleris, 1976: 565.

8 Kalleris, 1976: 554.

9 Le Bohec-Bouhet, 2011: 509

10 Hatzopoulos, 1994: 89; Wallbank, 2002: 80; Graekos, 2011: 78.

11 Nilsson, 1906: 403-408. Baege, 1923: 225-226.

12 El término viene del griego $\Xi \alpha v \theta$ ó $\zeta$, que significa rubio.

13 Grimal, 2008: 44-45. Hard, 2008: 231-232.

14 Usener; 1913: 439-441. Tarn, 1928: 197-198. Granier, 1931: 22-24.

15 Molina Marín, 2014: 82.

16 Goukowsky, 2009: 100-122.

17 Muller, 1820: 304. Kalleris, 1976: 237-238 y 265. Chrysostomou, 1993-1994: 197.

18 Apolodoro, I-4. Ovidio, Metamorfosis, 438-451

19 Hatzopoulos, 1994: 92. 
Si acudimos a las fuentes históricas, Polibio nos da una interesante noticia sobre Janto: "Los macedonios ofrecen sacrificios funerarios a Janto y hacen una lustración cabalgando sus caballos armados" (XXIII 10. 1720).

Es difícil determinar si esta referencia está vinculada con la ceremonia de las Jándicas. Goukowsky ha introducido un matiz importante en la traducción del pasaje de Polibio por el que, según él, los macedonios no harían la lustración cabalgando sobre sus caballos, sino que serían los propios caballos pertrechados para la guerra los que serían sacrificados ${ }^{21}$, lo que introduce una variación importante sobre la ceremonia descrita por Curco Rufo y Tito Livio.

Sea como fuere, lo que parece indudable es que la ceremonia objeto de nuestro estudio se componía de dos partes: una, la purificación mediante el sacrificio de una perra y desfile posterior sobre sus restos y la otra, el combate ritual. El acto central de las Jándicas parece, sin duda, el combate ritual. El rito de purificación se presenta como la condición indispensable para participar en el combate, que como hemos descrito, exigiría una expiación previa, pero no parece ser exclusivo de este festival.

\section{LOS SACRIFICIOS CANINOS EN LA ANTIGUA GRECIA}

Tenemos referencias interesantes en las fuentes antiguas sobre el ritual del $\pi \varepsilon \rho \iota \sigma \chi \nu \lambda \alpha \kappa \iota \sigma \mu o ́ \varsigma$ (periskylakismos - descuartizamiento de un perro), concretamente en Plutarco y Pausanias. En sus Moralia, el primero de ellos nos proporciona tres fragmentos de gran interés. Uno de los pasajes dice así:

Así como los griegos sacrifican una perra a Hécate, también los romanos la sacrifican a Geneta con ayuda de sus familiares. Sócrates dice que los argivos sacrifican una perra a Ilionía por razón de la facilidad de su parto. Y lo de la súplica de que ninguno sea «bueno», acaso se refiere no a los miembros humanos de una familia sino a los perros. Pues los perros deben ser fieros y temibles $\left(277 b^{22}\right)$.

En otro fragmento de la misma obra, al hablar de las Lupercalias, nos dice que:

Y casi todos los griegos utilizaban al perro y algunos lo utilizan aún hoy como víctima de sacrificio en las ceremonias de purificación. Y traen a Hécate cachorrillos junto con otras cosas de purificación y frotan con los cachorros a quienes necesitan purificarse y llaman a tal tipo de purificación periskylakismos (280c).

Por último, mostramos otro pasaje que aporta mucha información para nuestro propósito:

De cierto, los antiguos pensaban que este animal no era totalmente puro. Pues no se lo sacrificaban a ningún dios olímpico y cuando lo enviaban como cena a la subterránea Hécate en el cruce de caminos incluía parte de rito catártico y parte de rito apotropaico. En Esparta sacrifican cachorros a Enialio, el más sanguinario de los dioses. Y entre los beocios es rito público de purificación pasar entre las partes de un perro que ha sido cortado en $\operatorname{dos}^{23}$. Los romanos sacrifican un perro en el mes de la purificación (290d).

\footnotetext{
20 Versión traducida al castellano por Manuel Balasch Recort para Gredos. Madrid, 1983.

21 Goukowsly, 2009: 95.

22 Traducción al castellano de Concepción Morales Otal y José García López para Gredos. Madrid, 1992.

23 Peleo también hace un ritual parecido, pero esta vez con una mujer, Astidamía, a la que, según Apolodoro, "le dio muerte y después de separar sus miembros hizo pasar al ejército entre ellos hacia la ciudad" (III, 6-7).
} 

lles:

El fragmento de Pausanias, en el que nos habla de Laconia, es también muy rico en deta-

Los efebos realizan también estos otros actos: hacen sacrificios antes de la batalla en el Febeo. El Febeo está fuera de la ciudad, no muy lejos de Terapne. Allí cada grupo de efebos sacrifican un cachorro hembra de perro a Enialio, juzgando que al más valiente de los dioses el más valiente de los animales domésticos es una víctima de su gusto. No sé de ningunos otros griegos que acostumbren a sacrificar cachorros de perro, excepto los de Colofón. Éstos sacrifican también un cachorro hembra negro a la diosa Enodia. Tanto el sacrificio de los de Colofón como el de los efebos de Lacedemonia tienen lugar de noche (III 14. 9-1024).

En estos testimonios observamos que la práctica del sacrificio de perros como ritual de purificación parece extendida entre los griegos, al menos hay evidencias de ello entre los argivos, los espartanos, los tebanos y los habitantes de Colofón. Esta costumbre podría tener relación con un principio de magia basado en la ley de contagio, por la que las impurezas del ser humano, al contacto con la sangre impura del animal sacrificado, son absorbidas y expiadas ${ }^{25}$.

En el caso de Esparta se sacrificaban sendos perros a Enialo, epíclesis de Ares, uno por cada bando en vísperas de la batalla del Febeo, lo que supone una variación importante respecto del ritual que analizamos ${ }^{26}$. Pero este hecho no siempre parece circunscrito al ámbito militar, en el caso de los argivos, la víctima se consagraba a Ilionía para facilitar el parto ${ }^{27}$ y en el caso de Tebas, ceremonial muy similar al descrito en las Jándicas -los beocios pasaban entre los restos de la perra descuartizada-, se nos especifica que era un ritual público, aunque no se concreta en honor de qué divinidad.

Mención especial merecen las otras dos divinidades citadas por estas fuentes históricas en el contexto de los sacrificios caninos: Enodia y Hécate. La primera es muy relevante para el objeto de este estudio pues se trata de una divinidad local con un gran arraigo en Tesalia y Macedonia. Su distribución está acreditada arqueológicamente en las tierras altas, concretamente en el santuario de Exochi - Eordia_- en el monte Vermio, Elimea y Oréstide, así como en inscripciones originarias de Kozani y Beroia ${ }^{28}$. Sin embargo es en Tesalia donde la huella de esta diosa es predominante. Podemos hablar de un centro de culto de gran importancia en Feras, donde se ha documentado un templo originario del periodo geométrico ${ }^{29}$, pero también se han encontrado inscripciones en Pagasas, Larisa, Falana, Demetrias, Pition, Gonos y Tebas de Ftiótide ${ }^{30}$. En total hablamos de más de 30 inscripciones entre ambos territorios, lo que nos obliga a detenernos en el análisis de su posible vinculación con este ritual de purificación del ejército ${ }^{31}$.

Respecto a Hécate, diosa de culto más generalizado en Grecia y mencionada también en estos pasajes, cabe señalar que tanto en las fuentes históricas como en el registro arqueológico aparece vinculada o asimilada a Enodia en el ámbito cultural tesalio y macedonio, lo que nos obliga a detenernos también en este punto para determinar si estamos ante dos nombres de una

\footnotetext{
24 Traducción al castellano de Mari Cruz Herrero Ingelmo para Gredos. Madrid, 1994.

5 Frazer, 2011: 23-24.

Le Bohec-Bouhet, 2011: 510.

27 El texto de Plutarco se refiere a Ilionía, quizás otro nombre con el que se conocía a otra divinidad más famosa:

28 Chatzinikolaou, 2010: 193-222.

29 Chrysostomou, 1998: 268-271. Mili, 2015: 269-270.

Graninger, 2006: 182.

Chrysostomou, 1998. Graninger, 2006: 187-201.
} Ilitía. 
misma divinidad o ante la posibilidad de que Enodia fuera una epíclesis relacionada con un aspecto concreto de los atributos de Hécate.

\section{ENODIA Y HÉCATE: UN ANÁLISIS DE SUS EQUIVALENCIAS}

Dubois ha propuesto para el término Enodia un origen etimológico vinculado con las encrucijadas. Su nombre significaría, literalmente, "en el camino", tesis que comparte también Mili $^{32}$. Esta lectura nos permitiría relacionar a esta diosa con Hécate, que aparece tradicionalmente en la mitología griega como la protectora de $\operatorname{caminos}^{33} \mathrm{y}$, lo que resulta más destacable, relacionada en este sentido con los sacrificios caninos, tal y como describe Pausanias en el fragmento que sobre esta cuestión acabamos de citar en el epígrafe anterior.

Si recurrimos a las fuentes históricas encontramos que en la tragedia Helena, de Eurípides, autor que tuvo una estrecha relación con Macedonia, reino en el que murió en época del rey Arquelao $^{34}$, sus nombres aparecen como sinónimos en un diálogo entre Menelao y Helena iniciado por el primero: "Oh, Hécate, portadora de antorchas, envíame visiones favorables", a lo que Helena responde: "no soy un fantasma nocturno al servicio de Enodia" (569-570 35 ).

En un fragmento relativo a la párodos de Cortadoras de raices, de Sófocles, que Calvo Martínez utiliza para investigar la asociación de Hécate con la luna ${ }^{36}$, se hace referencia a la "lanza de la Enodia Hécate" (frag. 535.2), expresión que parece identificar a ambas diosas, en la misma línea que Eurípides.

Como refuerzo de estos testimonios históricos podemos recurrir a la iconografía. Enodia aparece representada con una antorcha en la mano, acompañada por un caballo y un perro. Así se muestra en sendos relieves, uno encontrado cerca de la moderna villa de Hagia Paraskevi, en Elimea, en la que se representa a la diosa sentada sobre el equino; y otro conservado en la colección arqueológica de Kozani, en la que se muestra de pie ${ }^{37}$. De este mismo estilo es el relieve encontrado en Cranón, Tesalia, conservado en la actualidad en el British Museum ${ }^{38}$.

Chrysostomou ha llamado la atención sobre la presencia de restos arqueológicos relacionados con Enodia en las proximidades de las necrópolis ${ }^{39}$. Además, a juzgar por la descripción de los funerales de Patroclo en la Ilíada, los caballos y los perros solían acompañar a los guerreros en sus piras crematorias en tiempos heroicos:

Entre grandes gemidos, arrojó decididamente a la pira cuatro caballos de altiva cerviz. Contaba además el soberano Aquiles con nueve perros que alimentaba a su mesa, de los cuales cogió a dos, y cortándoles la garganta, les echó también a la pira (XXIII, 170 $\left.{ }^{40}\right)$.

32 Dubois, 1987: 18. Mili, 2015: 147-158.

33 Las referencias en las fuentes a Hécate como protectora de caminos son abundantes. En el Himno Órfico a Hécate, de Porfirio, se dice: "invoco a Hécate, protectora de los caminos, en las encrucijadas..." (Traducción al castellano de Miguel Periago Lorente para Gredos. Madrid, 1987). También aparece así en los Papiros Mágicos griegos, IV, 1431-1433 o 2713-2734 (traducción al castellano de José Luis Calvo Martínez y María Dolores Sánchez Moreno para Gredos. Madrid, 1987). La relación de Hécate con los caminos también ha sido puesta de manifiesto por autores modernos, Grimal, 2008: 225 y Hard, 2008: 260. Para un estudio completo de Hécate se puede acudir a Calvo Martínez, 1992: 71-82; Mazzola, 2006: 305-318; Ronan, 1992, Rudolf, 1999 y Serafini, 2015.

34 Arquelao I reinó en Macedonia entre los años 413 y el 399 a.C.

35 Traducción al castellano de Alfonso Martínez Díez para Gredos. Madrid, 1998.

36 Calvo Martínez, 1992: 74.

37 Chatzinikolaou, 2010: 211.

38 Molina Martín, 2014: 39.

39 Chrysostomou, 1998: 25-48.

40 Traducción al castellano de Óscar Martínez García para Alianza Editorial. Madrid, 2010. 
Efectivamente, desde tiempos arcaicos, el caballo y el perro han sido animales vinculados con los difuntos, el mundo infernal y los imperios invisibles de las divinidades terrestres o selénicas. El caballo podía guiar el alma del muerto, de ahí que aparezca asociado a contextos funerarios ${ }^{41}$. De igual manera, el perro desempañaba también el papel de psicopompo $^{42}$, asociación que se manifiesta de forma clara en Egipto a través del dios Anubis, cinocéfalo. El testimonio de Plutarco en su Isis y Osiris es muy esclarecedor:

Neftis representa lo que está bajo la tierra y no se ve; mientras que Isis representa lo que está sobre la tierra y se ve; y el círculo que separa lo uno de lo otro, llamado horizonte, común a ambos, recibe el nombre de Anubis y está representado por una forma semejante a la del perro, pues el perro puede ver por igual tanto durante la noche como durante el día. Y consideran los egipcios que esa facultad -que es como la que consideran los griegos que posee Hécate- la posee Anubis porque es tanto una deidad del mundo inferior como un dios del Olimpo $\left(44^{43}\right)$.

Plutarco atribuye a Hécate un carácter psicopompo, en virtud del cual aparece habitualmente representada como portadora de antorchas - en calidad de la que recibe el apelativo de Phosphoros - , tal y como encontramos también a Enodia en los restos arqueológicos que nos han llegado. Pero yendo más lejos, la propia Hécate aparece citada, ya de forma tardía, como "diosa canicida", en Licofrón (Alejandra, 76-7744) o como "perra negra", en el papiro parisino de textos mágicos griegos, conocido como Supplementum Graecorum 574 de la Biblioteca Nacional, de la primera mitad del siglo IV d. C. (Papiro IV, 1431-1433 ${ }^{45}$ ).

En Exochi se localizó un pequeño altar dedicado por Nicandro a Enodia en el que no se representa a la diosa, pero sí aparecen un perro y una luna en fase creciente ${ }^{46}$. En este sentido conviene destacar que el perro fue considerado también la epifanía de la diosa lunar desde tiempos remotos. Gimbutas llamó la atención sobre la gran cantidad de figurillas caninas de mármol, cristal de roca y terracota, que representaban la totalidad del animal o solo su cabeza, en vasijas de culto datadas entre el IV milenio y el III milenio a. C. Así lo vemos por ejemplo en Gomi Pasarel (Bulgaria), Cucuteni (Rumanía) o Lengyel (antigua Checoslovaquia). En este contexto, el perro a veces se asociaba al árbol de la vida, como animal custodio ${ }^{47}$.

En el caso concreto de Macedonia, tenemos frecuentes representaciones de perros en estelas funerarias, como la encontrada en Pella, dedicada a un niño de nombre Xanthos, hijo de Demetrios y Amadika, datada en el siglo V a. C., en la que se representa al fallecido con un pájaro en la mano y un perro a sus pies. El tema es repetido en otras estelas funerarias, como la de Antígono o las encontradas en Pella, Dion o Tesalónica ${ }^{48}$. Resulta pertinente destacar también la figurilla de un perro de terracota encontrada en la tumba del guerrero de la necrópolis de Archontiko. ${ }^{49}$

En un pequeño santuario rural al sur de Oréstide, en Liknades, en el monte Voion, se encontró una estatua tricéfala idéntica a los hekateia localizados en otras partes de Grecia ${ }^{50}$. Una

41 Chevalier y Gheerbrant, 2007: 208-209.

42 Chevalier y Gheerbrant, 2007: 816.

43 Traducción al castellano de Francesc Gutiérrez para Olañeta. Palma de Mallorca, 2007.

44 Traducción al castellano de Manuel y Emilio Fernández-Galiano para Gredos. Madrid, 1987.

45 Traducción al castellano de José Luis Calvo Martínez y María Dolores Sánchez Moreno para Gredos. Madrid, 1987.

46 Chatzinikolaou, 2010: 212.

47 Gimbutas, 2014: 210-213.

48 Le Bohec-Bouhet, 2011: 496-497.

49 Chrysostomou, 2011: 340 .

50 Chatzinikolaou, 2010: 210. Grimal, 2008: 225. Hard, 2008: 261. Es destacable este fragmento de Pausanias, donde se refiere de forma explícita al momento en el que parece haber un cambio en la representación de Hécate: “de los dioses, 
escultura similar fue hallada en las proximidades del monte Vermio ${ }^{51}$. Theodora HadzisteliouPrice remonta el origen de esta representación a la necesidad funcional de proteger los cruces de caminos $^{52}$, sin embargo, otros autores vinculan esta tricefalia a su relación con la luna y sus diferentes fases de crecimiento-decrecimiento ${ }^{53}$. En esta línea, Baring y Cashford señalan la posibilidad de que Artemis, Hécate y Selene formen una trinidad relacionada con el astro lunar. De esta manera, la diosa cazadora sería la luna creciente, Hécate sería la luna nueva y la última, la luna llena ${ }^{54}$. Campbell propone como alternativa que este aspecto triple tenga relación con tres manifestaciones de la misma diosa, una celeste (Selene), otra telúrica (Artemis) y otra ctónica (Hécate) ${ }^{55}$.

Para el objeto de este estudio resultan de gran interés las dedicatorias que encontramos en Tesalia a Artemis Pheraia $^{56}$, que ponen en relación a esta diosa con la ciudad de Feras y, por tanto, con el culto a Enodia. En el Catálogo atribuido a Hesíodo nos encontramos con referencias a Artemis Hécate ${ }^{57}$, mientras que la arqueología nos revela también el culto a Artemis Enodia, que parece haber sido venerada como tal en el santuario de Pasikrata, en Demetrias ${ }^{58}$. Artemis se relaciona también con los perros, como podemos ver, por ejemplo, en el mito de la muerte de Acteón atacado por sus propios animales de caza ${ }^{59}$. Hasta tal punto han llegado a identificarse ambas divinidades, que Marija Gimbutas habló abiertamente de una diosa Artemis-Hécate, que habría tenido su origen en Asia, como potnia theron y se habría fusionado con la hermana de Apolo al incorporarse en el mundo griego dando lugar a una divinidad de carácter dual, símbolo de vida y de muerte, de las potencias creadoras y destructoras de la naturaleza ${ }^{60}$.

Este carácter dual, a caballo entre la vida y la muerte, explicaría también la relación que tanto Hécate como Enodia tienen con la cría de jóvenes. En la Teogonía de Hesíodo se dice respecto a la primera lo siguiente:

El Crónida la hizo criadora de los jóvenes que después de ella vieron con sus ojos la luz de Eos que a muchos alumbra. Así, desde el comienzo, es criadora de jóvenes y éstas son sus esferas de actuación (450-453) ${ }^{61}$.

Wilamowitz vinculó también a Enodia con la cría de niños ${ }^{62}$, hecho fácilmente constatable puesto que aparece como tal en 16 de las inscripciones dedicadas a la diosa que han sido encontradas en Tesalia, recopiladas por Chrysostomou y Graninger ${ }^{63}$.

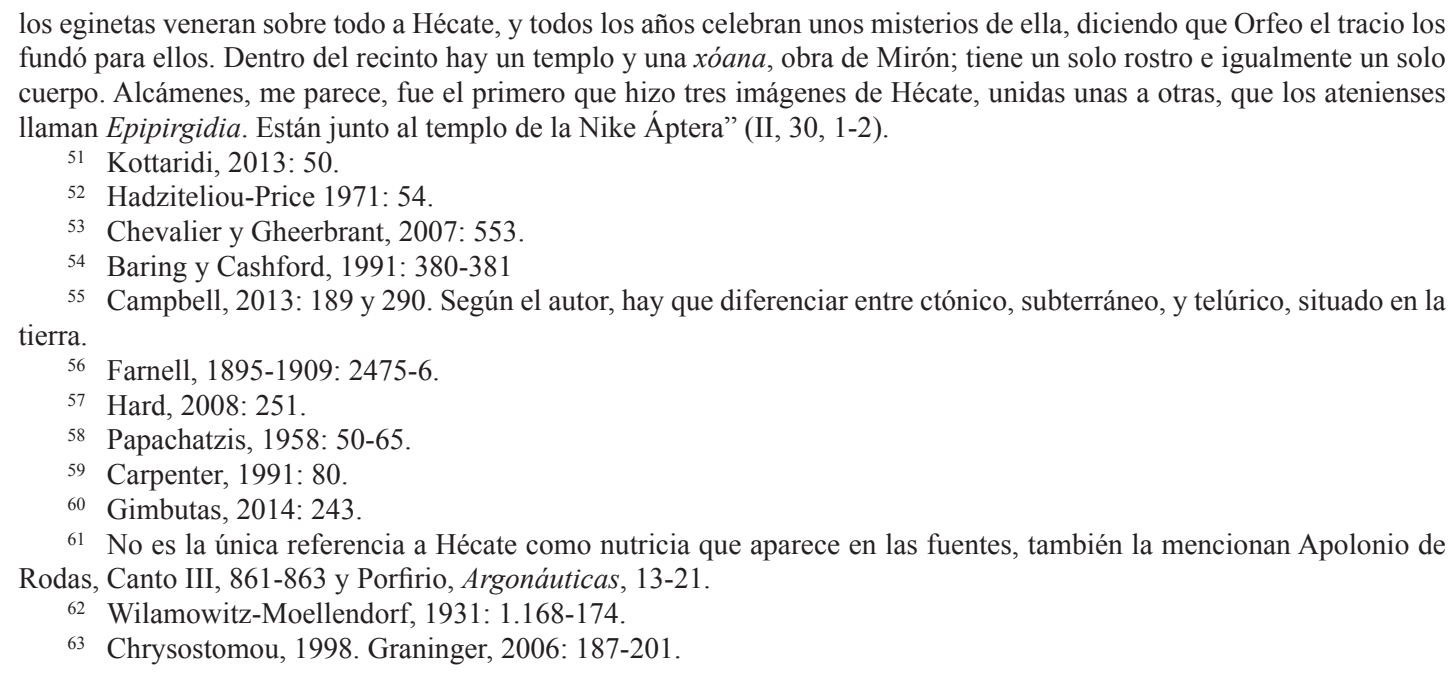


Un último punto de conexión entre ambas divinidades lo encontramos en la hechicería ${ }^{64}$. Un fragmento de Medea, de Eurípides, en el que la joven sacerdotisa recomienda a Jasón cómo propiciar a Hécate para conseguir una inmensa fuerza, resulta muy revelador:

$\mathrm{Al}$ alba humedece esta pócima y, desnudo, acicala tu cuerpo como con un ungüento. Con ella obtendrás una fuerza inmensa y un gran vigor, y podrías decir que te asemejas no a los hombres sino a los dioses inmortales (Canto III, 1030-104565).

Polieno, en Estratagemas, nos relata una anécdota en la que se echa mano de la hechicería para conquistar una ciudad. En este caso, la protagonista es Enodia:

Cnopo, del linaje de los codridas, estaba en guerra con los que ocupaban Eritras. El dios le profetizó que tomara de los tesalios como general a la sacerdotisa de Enodia. Él envió una embajada a los tesalios y les reveló el oráculo del dios. Y éstos le enviaron a Crisame, sacerdotisa de la diosa. Ella, que era experta en drogas, cogiendo al toro más grande y hermoso de la manada, le cubrió de oro los cuernos y le adornó el cuerpo con cintas y ropajes de púrpura recamados en oro y, mezclándole en la comida una droga enloquecedora, se la dio a comer $\left(43^{66}\right)$.

El alto número de equivalencias que observamos entre ambas divinidades descarta, en nuestra opinión, que Enodia sea una simple epíclesis de Hécate relacionada con los cruces de caminos, puesto que sus atributos van más allá, hasta prácticamente ser equivalentes en todas sus dimensiones. La única variación entre ambas, que podríamos considerar como un desarrollo puramente local, es la incorporación del caballo a su iconografía ${ }^{67}$. Se trata de un animal tan importante en Macedonia, y también en Tesalia, que fue cantado por Eurípides en las Bacantes $^{68}$ y constituyó un aliado fundamental para la caza y la guerra en ambos territorios, pero cuya asociación a contextos funerarios no desentona con el entorno en el que encontramos habitualmente a la diosa tricéfala, incluso aparece relacionado con Janto, como veíamos en la cita de Polibio.

Kraus traza una historia del culto a Hécate por la que desde su Caria originaria habría entrado en Grecia a través de Tracia — asociada con la diosa cazadora Bendis y con Zerintia, divinidad de componente orgiástico — hasta llegar a Tesalia, donde habría arraigado con vigor en Feras ${ }^{69}$. Aquí se habría unido a la diosa local Enodia, dando lugar a otra divinidad, asociada

64 Sobre la vinculación de Hécate con la hechicería tratan prácticamente todos los autores que abordan el estudio de la diosa. Recomendamos las obras de Kraus, 1960; Ronan, 1992; Calvo Martínez, 1992: 71-82; Bermejo Barrera, 2001: 15-28; Molina Martín, 2014 y Serafini, 2015.

${ }_{65}$ Traducción al castellano de Alberto Medina González y Juan Antonio López Pérez para la misma editorial. Madrid, 2000.

${ }_{66}$ Traducción al castellano de José Vela Tejada y Francisco Martín García para Gredos. Madrid, 1991.

67 En desarrollos tardíos de Hécate también aparece asociada a los caballos, por ejemplo en Argonáuticas de Porfirio: "con ella venía la hija de Tártaro, Hécate, de formas cambiantes, tricéfala, prodigio funesto de ver, indestructible, de su hombro izquierdo salía un caballo de larga crin y, a su derecha, se podía contemplar una perra de mirada furiosa; en medio, una figura de aspecto salvaje sostenía en ambas manos unas espadas provistas de empuñadura. De un lado a otro, en torno al hoyo, se movían en círculo Pandora y Hécate; las acompañaban apretujándose las vengadoras" (975-983).

68 "Oh Pieria bienaventurada, / te venera Evio y a ti llegará / para danzar con sus coros / de bacantes, y a la Ménade / trepidante guiará después de cruzar / el Axio de rápida corriente / y el padre Lidias, que / la dicha de la felicidad a los mortales / otorga y del que oído decir / que una tierra de buenas caballos / con sus aguas hermosísimas abona" - Eurípides, Bacantes, 565-574.

69 Este hecho sería corroborado por la ubicación geográfica de los sacrificios caninos a Enodia, situados por Pausanias en Colofón, Asia Menor, cerca del famoso santuario de Hécate en Lágina, citado por Estrabón. Al hablarnos de Estratonicea, el geógrafo e historiador griego nos dice que "es un asentamiento de los macedonios" y a continuación explica: "también ella fue adornada por los reyes con suntuosas construcciones. En el territorio de los estratoniceos hay dos santuarios, el famosísimo de Hécate en Lagina, que celebra grandes festivales anuales, y cerca de la ciudad el de Zeus 
con Artemis, Selene y Perséfone, como veíamos ${ }^{70}$. Philippson, también sigue la pista tesalia, pero para él no solo se unió a Enodia, sino también a Ferea ${ }^{71}$. Otro autor que apuesta por una Hécate asimilada a Enodia en Tesalia es Wilamowitz ${ }^{72}$.

Chrysostomou, por el contrario, ha sugerido para Enodia un origen genuinamente tesalio, pues la considera una divinidad tutelar de Feras, desde donde se habría expandido al resto de Tesalia y Macedonia a partir del siglo IV a. C. ${ }^{73}$ Nilsson, que inicialmente consideraba a Enodia como una simple epíclesis de Hécate, acabó por convencerse de que la diosa estaba presente en lugares en los que no existían testimonios de su supuesto equivalente, por lo que apostó por dotarle de una entidad propia ${ }^{74}$. En sentido opuesto, Mastrokostas ha sugerido un origen macedonio, hipótesis que argumenta en base a un epigrama funerario de una sacerdotisa de esta diosa datado en la primera mitad del siglo IV a. C. ${ }^{75}$, mientras que Mazon, que habla de Hécate, sugiere un origen beocio ${ }^{76}$.

Enodia se ha vinculado también con otras divinidades, aunque en estos casos aparece claramente diferenciada: Zeus Meilichios, un dios de carácter ctónico, con quien aparece en algunas inscripciones en Feras y Larisa ${ }^{77}$; Perséfone - ya que Hécate fue la única testigo de su rapto por $\mathrm{Hades}^{78}$, lo que le hace aparecer estrechamente vinculada con ella-, aspecto muy relevante en el ámbito macedonio, en el que el rapto de la hija de Demeter es un tema iconográfico recurrente ${ }^{79}$ y Zeus Thaulios, que purificaba los homicidios ${ }^{80}$. Sin embargo, para el objeto de este estudio la vinculación que más nos interesa es la de Enodia y Apolo Xanthios, desarrollada por Chrysostomou, quien relaciona a la diosa con el ejército y la guerra gracias al contenido del epigrama de un poeta anónimo a Filipo $\mathrm{V}^{81}$. Conviene, por tanto, analizar los atributos que pueden vincular a Enodia-Hécate con el mundo militar y rastrear las vías por las que pudo incorporarse a la ceremonia de las Jándicas.

Crisaoreo, común a todos los carios y en el que se reúnen para hacer sacrificios y deliberar sobre cuestiones comunes" (XIV, 25-1). Traducción al castellano de María Paz Hoz García-Bellido para Gredos. Madrid, 2003.

70 Kraus, 1960: 19-23, 61.

71 Philippson, 1944: 72-73, 77.

72 Wilamowitz-Moellendorf, 1931: 1.168-174.

73 Chrysostomou, 1998: 268-271. Robert, 1960: 588-595. Morgan, 2003: 135-155 (en asociación con Zeus Thaulios).

74 Nilsson, 1961: 90-91. Nilsson, 1961-1967: 1.723 n4.

75 Mastrokostas, 1978: 196-197.

76 Mazon realizó un importante estudio de la obra de Hesíodo y, por tanto, prestó una atención especial a Hécate, a la que se dedica un himno en la Teogonía. La describe como una diosa próxima a una potnia theron, similar a la divinidad de Tespias. Aparecería representada en un ánfora beocia del siglo VIII a.C. (Mazon, 1923: 22). Su aspecto benévolo, muy diferente al que adquiriría en las referencias posteriores, se debería, según Burkert, a que el autor beocio era un devoto seguidor de la diosa (Burkert, 2007: 231).

77 Chrysostomou, 1993-1994: 183. Graninger, 2006: 190-195. Chatzinikolaou, 2010: 214.

78 En el Himno homérico a Deméter, que se ha fechado entre finales del siglo VII y comienzos del VI a.C., Hécate aparece como la única que oyó los lamentos de Perséfone al ser raptada por Hades para ser conducida al infierno en su carro: "ninguno de los inmortales ni de los hombres mortales oyó su voz, ni siquiera los olivos de hermosos frutos. Sólo la hija de Perses, la de ingenuos sentimientos, la oyó desde su antro: Hécate, la de brillante tocado (y asimismo el soberano Sol, el ilustre hijo de Hiperión), cuando la muchacha invocaba a su padre, el Crónida" (23-28). Poco después, sale al paso de Deméter, mientras buscaba desesperada a su hija, alumbrada por antorchas para decirle que escuchó los gritos de la joven, pero no vio a quien la secuestraba (53-59). En la última referencia que encontramos en esta obra, Hécate aparece estrechamente vinculada a Perséfone, con la que compartía "alegrías", se la menciona como la de "brillante diadema" y nos dice que la soberana "la precede y la sigue" (438-440). Traducción al castellano de Alberto Bernabé Pajares para Gredos. Madrid, 1978.

79 Cabe recordar la espléndida escena del rapto de Perséfone del respaldo del trono de la tumba de la reina Eurídice, en Egas; el fresco de la tumba de Perséfone o el mosaico del suelo de la cámara funeraria de la recientemente descubierta tumba del túmulo de Kastá, en Anfípolis.

80 Chrysostomou, 1993-1994: 184-187. Morgan, 2003: 135-155.

81 Gow-Page, 1965: I-IX, 3918-392 en Chrysostomou, 1993-1994: 200-201. 


\section{ENODIA, HÉCATE Y EL EJÉRCITO}

La Teogonía de Hesíodo, fechada entre los siglos VIII y VII a. C., en su Himno a Hécate, la describe de la siguiente manera:

Cada vez que alguno de los hombres sobre la tierra quiere atraerse el favor de los dioses, realizando hermosos sacrificios según la costumbre, suele invocar a Hécate. Mucha honra acompaña a aquel cuyas súplicas acepta benévola la diosa y le otorga, además, felicidad, puesto que tiene capacidad para ello $\left(412-421^{82}\right)$.

Un poco más adelante, Hesíodo desarrolla sus atributos:

En el juicio se sienta junto a los venerables reyes y en el ágora hace sobresalir al que quiere; cuando para la destructora guerra se preparan los hombres, entonces la diosa asiste a los que desea otorgar la victoria y concederles la gloria. Asimismo es útil cuando los hombres compiten en un certamen, pues también la diosa les asiste y ayuda y, al vencer en fuerza y capacidad, un hermoso premio con facilidad y alegría se lleva y a sus padres da gloria. Es capaz de asistir a los jinetes que quiere (434-438).

Otro beocio, Píndaro, que escribió en el siglo V a. C., la menciona en uno de sus peanes y, lo que resulta muy interesante para este estudio, asociada de nuevo a la guerra y en particular a los abderitas, habitantes de Abdera, ciudad situada al noroeste de Macedonia:

Pero a ella, a la tropa llegada junto al río, dispersará el que con pocas armas salió contra copioso ejército. Era del mes el día primero: la virgen de purpúreos pies, la diosa Hécate benevolente, anunció que esa palabra tendría de grado que cumplirse (II 52b, 73-7983).

La ya comentada relación de Enodia con la cría de jóvenes podría sugerir que fuera invocada en las Jándicas en el contexto de un rito de paso, en línea con la tesis de Hatzopoulos ${ }^{84}$. En este sentido, los nuevos reclutas traspasarían el umbral delimitado simbólicamente por los restos de la perra sacrificada para purificarse e integrarse entre los soldados veteranos de cara a una próxima campaña militar. Podría considerarse una extensión de la ephebeia, el rito por el cual los niños se convertían en adultos mediante la caza de un animal por sus propios medios ${ }^{85}$. A favor de esta hipótesis se puede plantear el valor simbólico de las encrucijadas, el dominio de la diosa a la que se consagraba el sacrificio, pues son el lugar en el que el hombre debe elegir un camino en detrimento de otro y, por tanto, se da un paso decisivo hacia el encuentro con el destino ${ }^{86}$. Por el contrario, se puede argumentar que era todo el ejército el que participaba en la ceremonia, que no tenía que estar vinculada de forma necesaria a un rito de paso pues, como hemos visto, podía ser convocada por el rey en caso de necesidad, aunque con los datos que manejamos hasta este momento nada puede afirmarse con total certeza.

82 Traducción al castellano de Adelaida Martín Sánchez y María Ángeles Martín Sánchez para Alianza Editorial. Madrid, edición 2013.

83 Traducción al castellano de Alfonso Ortega para Gredos. Madrid, 1984.

84 Hatzopoulos, 1994: 55.

85 Graekos, 2011: 78. Plutarco nos describe un rito de paso semejante para los espartanos (Licurgo, 28).

86 Chevalier y Gheerbrant, 2007: 448-339. 


\section{LOS MISTERIOS DE SAMOTRACIA}

Desde el punto de vista de la dinastía argéada, cuyos miembros eran los ejecutores principales del festival objeto de estudio, es importante hablar de la vinculación de la diosa Hécate con los misterios de Samotracia, como luego veremos. En la Alejandra de Licofrón, autor que trabajó en la Biblioteca de Alejandría hacia el siglo III, se nos habla de Hécate en estos términos:

La virgen trimorfa, Brimo, te hará perra que asusta por las noches ladrando a los mortales que no honran con desfiles de antorchas a la efigie de la dueña cerintia del Estrimón ni aplaquen, haciendo sacrificios, la diosa ferea (Alejandra, 1175-1180).

En este fragmento, Licofrón se refiere a Hécate como Brimo ${ }^{87}$ y ferea — palabra referida, con toda probabilidad, a su origen: Feras-, pero también nos dice que es la dueña cerintia del Estrimón. La explicación al apelativo cerintia la encontramos en un pasaje anterior de la misma obra, en la que nos habla de la "cueva cerintia de la diosa canicida" (Alejandra, 7677), en clara alusión a la cueva de Cerinto, situada en la isla de Samotracia, de la que Nono de Panópolis, en Dionisíacas, nos dice:

Cerinto, poblada por los insomnes Coribantes, y fundada por la renombrada Pérsida en el lugar donde se hallan los peñascos sagrados que visitan los iniciados de la Doncella ${ }^{88}$, con sus antorchas (XIII, 400-403 ${ }^{89}$ ).

Hay otras dos notas destacables en el testimonio de Licofrón: el apelativo canicida, es decir, asesina de perros, que aparece vinculado, de forma muy probable, a los sacrificios que se hacían en su honor en el interior de esta cueva y la referencia al Estrimón, un importante río situado en la franja fronteriza entre Macedonia y Tracia.

Nos quedamos con el testimonio del egipcio Nono de Panópolis, cuya obra se ha situado en el siglo V d. C. En ella aparecen más referencias a Hécate vinculadas al contexto de los misterios de Samotracia, en los que se celebraba a la "divina Hécate, que ama a los cachorros" (III, 7576) y en los que el cábiro Alcón hacía girar su pica "en derredor del fuero del tíaso de Hécate" (XXIX, 214-215). En otro fragmento, nos dice: "¡Os saludo, antros de los Cábiros, y riscos de Coribantes! ¡Ya no veré la nocturna antorcha del tíaso de la madre Hécate!” (XLIV, 185-187)

Y más adelante continúa refiriéndose a la misma diosa:

¡Tú Selene, conductora del carro argénteo, si tú eres también llamada Hécate, la de muchos nombres, y en la noche empuñas la sagrada antorcha en tu mano portadora del fuego, acude a mí, noctámbula, criadora de sabuesos, pues te complace el sonido nocturno de los veloces perros con su aullar fúnebre! (XLIV, 192-197).

Como apunte, cabría destacar que estos honores con antorchas que debían rendirse a Hécate recuerdan, salvando las distancias, a los desfiles de antorchas que nos narran algunas fuentes históricas en relación con la campaña de Alejandro Magno. Así, en Quinto Curcio Rufo encontramos este interesante fragmento:

87 Hécate aparece como Brimo en las Argonáuticas de Porfirio, en las Argonáuticas de Apolonio y en el Protéptico de Clemente de Alejandría, relacionada en todos los casos con la cría de jóvenes.

88 La diosa Pérsida no es otra que Hécate, hija de Perses, y la Doncella es Perséfone.

89 Traducción al castellano de Sergio Daniel Manterola y Leandro Manuel Pinkler para Gredos. Madrid, 1995. 
Él (Alejandro), por su parte, subió a la cima de una elevada montaña y, a la luz de gran cantidad de antorchas, hizo un sacrificio, siguiendo la costumbre de su país, a los dioses tutelares de la región (III, 8-22) ${ }^{90}$.

\section{TESALIA Y MACEDONIA: UNA RELACIÓN ANCESTRAL}

La relación entre los territorios de Macedonia y Tesalia se remonta al primer neolítico. El asentamiento de Nea Nicomedia, situado en Macedonia central, al norte de Veria, ha arrojado una serie de restos materiales vinculados con la cultura proto-Sesklo, de origen tesalio ${ }^{91}$. Los contactos entre ambos territorios eran intensos en dos corredores: el del río Haliacmón, que desde el lago Prespa se prolonga hacia su desembocadura, y el del Bitola-Kozani, que se inicia en la llanura de Pelagonia y se extiende hacia el sur, pasando el cauce del Erigón, hasta las tierras del lago Vegoritis (Ostrovo), Lincéstide y Eordea, limitada al norte por el Monte Vermio y al sur por el Monte Vournio. Desde el primer corredor, a través de los afluentes del río Peneo, Macedonia se une con la planicie tesalia por los pasos de Kalabaka y Trikkala, que constituyen la principal vía de acceso desde el norte al centro de Grecia. Desde el segundo corredor, existen los pasos de Satista y de Volutsana, este último también de gran importancia ${ }^{92}$.

En tiempos históricos, los contactos entre tesalios y macedonios fueron también habituales, como es lógico entre poblaciones vecinas ${ }^{93}$. Tucídides y Diodoro Sículo nos hablan de estas relaciones con motivo de la ofensiva de Sitalces ${ }^{94} \mathrm{y}$, más tarde, para frenar el avance del espartano Iscágoras hacia el norte, donde se dirigía con contingentes de refuerzo para Brasidas ${ }^{95}$. Ambos acontecimientos durante el reinado de Pérdicas II, datado entre los años 454 y 413 a. C. En el 392 a. C., tras su llegada al poder, Amintas III tuvo que refugiarse en Tesalia por el avance de los ilirios ${ }^{96} \mathrm{y}$ más tarde, ya en época de Alejandro II, que reinó entre los años 370 y 368 a. C., el mismo Diodoro nos informa de la ayuda prestada por el monarca macedonio a la familia de los Alévadas, una de las más influyentes de Larisa ${ }^{97}$. Sin embargo es con Filipo II cuando esas relaciones van a reorientarse de forma radical, pues Tesalia será integrada dentro del reino de Macedonia.

Estos contactos en el ámbito político tienen su equivalente en el ámbito religioso, tal y como ha señalado Graninger, quien ha llamado la atención sobre la aparición de inscripciones con dedicaciones a dioses similares en ambos territorios, como es el caso de las encontradas en honor de Zeus Thaulios, cuyo culto estaba muy extendido tanto en Tesalia como en Macedonia o el culto a la misma Enodia. Este intercambio no era unidireccional, puesto que como también señala Graninger, la expansión del culto a Dionisos en Tesalia tiene su origen en su vecina del norte ${ }^{98}$.

\footnotetext{
90 No es la única referencia a desfiles de antorchas que aparecen en las campañas de Alejandro Magno, también tenemos en Flavio Arriano, II-5, II-24 y III, 16 y Plutarco, Alejandro Magno, 31-9.

91 Borza, 1990: 58-67.

92 Borza, 1990: 33-50.

93 Para profundizar en relación entre Tesalia y Macedonia es interesante Graninger, 2010: 309-313 (antes de Filipo II) y 313-318 (de Filipo II a Alejandro Magno).

94 Tucídides, II, 95-101 y Diodoro Sículo, 50-51.

95 Tucídides, IV, 132.

96 Diodoro Sículo, XIV, 92, 3-4. Según Demóstenes, en Contra Aristócrates, Amintas fue expulsado por los tesalios (111).

97 Diodoro Sículo, XV, 61.

98 Graninger, 2010: 324.
} 


\section{FILIPO II: EL REFORMADOR DEL EJÉRCITO MACEDONIO}

No tenemos ninguna información que relacione directamente a Filipo II con Enodia-Hécate, pero a través de algunos indicios podemos estrechar el cerco sobre la posibilidad de que hubiera sido el monarca macedonio el introductor de este culto en las Jándicas con motivo de la reforma del ejército que impulsó tras su llegada al poder, bien de forma directa, bien de forma indirecta.

Plutarco nos da cuenta de la participación de Filipo II en los ritos de iniciación de los misterios de Samotracia, en los que relata que conoció a su mujer, Olimpíade ${ }^{99}$. Incluso parece constatado que invirtió grandes sumas de dinero en la mejora del templo, lo que denotaría cierta devoción por las divinidades involucradas en el culto ${ }^{100}$. Pero también nos encontramos a Filipo relacionado con dos entornos en los que Enodia-Hécate estaba muy presente: Tebas y Tesalia.

Sabemos por las fuentes que Filipo II fue entregado como rehén al padre de Epaminondas ${ }^{101}$ y que recibió la misma educación que este de la mano de Lisis de Tarento, un maestro pitagórico anciano y severo ${ }^{102}$. Hemos visto cómo en Beocia, tierra de Hesíodo y Píndaro, cuyos testimonios sobre la diosa ya hemos apuntado, el culto a Hécate estaba muy arraigado y el sacrificio de perros como ritual público de purificación, muy extendido. Filipo pudo haber conocido en este entorno cierto tipo de rituales que luego aplicó en su reforma del ejército ${ }^{103}$, en la que tuvo muy presente su experiencia tebana.

Nos queda un tercer punto de conexión entre Filipo y Enodia, en esta ocasión a través de Tesalia. Graninger ha explorado el intento de los tiranos de Feras de cohesionar territorialmente a los tesalios en torno a dos divinidades: Apolo Pitio y Enodia. Mientras que el primero era una divinidad panhelénica, la segunda era una divinidad local cuyo culto fortalecieron en la ciudad, donde su santuario adquirió una gran importancia ${ }^{104}$.

Jasón de Feras llegó a potenciar tanto la figura de Enodia, que se acuñó moneda con su efigie, lo que ha hecho que Chrysostomou haya hablado de diosa nacional de los tesalios, aspecto que Mili y Graninger ponen en cuestión ${ }^{105}$. En Feras se han encontrado diez de las inscripciones tesalias dedicadas a la diosa. En una de ellas, hallada en Pagasas, puerto de Feras en la Antigüedad, aparece con el epíteto Patroa. Chrysostouomu mantiene que gracias a la acción de los tiranos, en especial Licofrón I, Jasón y Alejandro, Feras alcanzó la hegemonía política y militar de Tesalia, lo que permitió que el culto a Enodia se expandiera por un vasto territorio ${ }^{106}$.

Autores como Graninger mantienen que es arriesgado asegurar que el epicentro del culto a Enodia haya sido esta ciudad. Este autor argumenta su negativa por la presencia de Artemis Pheraia en Sición y Argos, lo que sabemos por referencias de Pausanias ${ }^{107}$ y el hecho de que las inscripciones encontradas en Larisa sean anteriores a las de Feras, lo que introduce una duda muy razonable. Lo que sí parece admitir Graninger es que el culto a Enodia se transformó

\footnotetext{
99 Plutarco, Alejandro Magno, 2-2.

100 En Ridgway, 2001, 26 se dice que Filipo fue el encargado de patrocinar los propileos del Santuario de los Grandes Dioses de Samotracia, pues su obra se ha datado entre los años 350 y 330 a.C. Plantea la posibilidad de que el friso de mujeres danzantes podría ser una alegoría de su matrimonio con Olimpíade.

101 Justino, VII, 5-3 y Diodoro Sículo, XVI, 2-2.

102 Cornelio Nepote, Epaminondas, 2-2.

103 Polieno. IV, 2-10

104 Graninger, 2009: 110-111.

105 Chrysostomou, 1998: 268. Mili, 2015: 269-270.

106 Chrysostomou, 1998: 100.

107 Graninger, 2009: 115-116. Pausanias, II, 10-7; 23-5.
} 
durante la época de los tiranos y se convirtió en una divinidad de tipo comunal ${ }^{108}$. Sea como fuere, lo que nos interesa es que Enodia fue una divinidad principal para los tiranos de Feras y los habitantes de la ciudad.

En el 358 a. C. Filipo dirigió un ataque sorpresa contra Alejandro de Feras, el tirano que gobernaba en Tesalia. Con esta ofensiva se hizo con el control de Larisa, ciudad residencia de los Alévadas, familia de gran reputación, a la que su hermano Alejandro ya había tratado de ayudar durante su reinado. El objetivo de esta ofensiva era el de incorporar a su ejército a los famosos jinetes tesalios, que jugarían un papel muy importante con posterioridad, tanto durante su reinado como en el de Alejandro ${ }^{109}$. Según Diodoro, un año más tarde, en el 357 a. C., los Alévadas se levantaron de nuevo contra Licofrón y Tisífono, que habían acabado con la vida de Alejandro de Feras en el 358 a. C. Una vez en el poder, los tiranicidas habían cambiado su manera de pensar, aglutinaron en su favor un importante ejército de mercenarios y retuvieron el gobierno por la fuerza. Filipo intervino en el conflicto derrotando a los tiranos y tratando con exquisita consideración al resto de ciudadanos, lo que le valió una sólida alianza, tanto durante su reinado, como durante el reinado de Alejandro ${ }^{110}$. Cabe pensar que parte del contingente tesalio que Filipo incorporó a su ejército al convertirse en tagos de la Liga Tesalia mantuviera su devoción por Enodia ${ }^{111}$ y que el monarca, decidido a favorecer su integración y reforzar la unidad de su ejército, permitiera la incorporación de un ritual de este tipo en la celebración del festival más importante del ejército.

Otro elemento que debemos tener en cuenta en este contexto es el matrimonio de Filipo II con dos mujeres tesalias procedentes de familias nobles de Feras y Larisa que, como hemos visto, eran ciudades en las que el culto a Enodia estaba bastante arraigado. El listado de las esposas de Filipo lo conocemos por un fragmento del biógrafo Sátiro del que se hace eco Ateneo, en el que describe la importancia política de sus enlaces. En el pasaje que nos interesa dice:

Entonces, como quería apropiarse también de los tesalios a través de la realeza, concibió hijos con dos mujeres tesalias, una de ellas era Nicesépolis de Feras, quien le dio a Tesalónica, y la otra, Filina de Larisa, con quien fue padre de Arrideo (III, 557b-e ${ }^{112}$ ).

A pesar de que Justino nos dice que Filina era una bailarina tesalia ${ }^{113}$, todo parece indicar, si seguimos el testimonio anterior y nos guiamos por el sentido común, que ambos matrimonios tenían una orientación diplomática que tenía como objetivo estrechar las relaciones entre ambos reinos.

Por último, hay un hecho que resulta muy significativo en relación con el posible culto a Hécate en Macedonia: su vinculación con Heracles. Como es sabido, la dinastía Teménida se consideraba descendiente del héroe tebano ${ }^{114}$, por lo que buena parte de la maquinaria propagandística que desarrolló estaba orientada a reforzar esa vinculación mítica entre sus miembros y el semidiós de cara al resto de macedonios. En este sentido resulta muy interesan-

108 Graninger, 2009: 118.

109 Justino, VII, 6-8.

${ }_{110}$ Diodoro Sículo, XVL, 14-1.

${ }_{111}$ Chrysostomou, 1993-1994: 196.

112 Ateneo, 3557b-e y Borza, 1990: 208.

113 Justino, IX, 8-2.

${ }^{114}$ La vinculación de la dinastía argéada con el Heracles tebano se produce a través de Témeno, de ahí que sean conocidos también como teménidas. Témeno era un heraclida hijo de Aristómaco y biznieto de Hilo, hijo de Heracles y Deyanira, según la genealogía más corriente. Junto a su hermano Cresfontes, le fue concedido conquistar el Peloponeso, tras lo que adquirió el derecho sobre Argos. Grimal, 2008: 500 y Hard 2008: 382-386. Para la genealogía mítica de los reyes de Macedonia puede consultarse Heródoto, VIII, 138-139; Veleyo Paterculo, I, 6, 5; Justino, VII, 1-7; Plutarco, Alejandro Magno, 2-1 y Flavio Arriano, IV, 11. 
te resaltar el dato de la posible vinculación de Hécate con dos episodios clave en la vida del héroe: su nacimiento y su apoteosis. En relación con su niñez, Hard ha señalado que según un relato del poeta helenístico Nicandro, Hécate hizo de la comadreja su animal de compañía por compasión de Galintias ${ }^{115}$, la criada pelirroja cuyo ingenio aceleró el nacimiento de Heracles y fue castigada por ello ${ }^{116}$. Por otro lado, Campbell ha llamado la atención sobre la aparición en época romana de representaciones de Hécate en el ritual de purificación de Heracles ${ }^{117}$, a cuya elevación al Olimpo asiste Hécate ${ }^{118}$.

\section{CONCLUSIÓN}

La festividad de las Jándicas, celebrada en el mes de Xanthikos, equivalente a nuestro mes de abril, tenía como fin rememorar el combate ritual protagonizado por Janto, un epíteto que podríamos vincular con diferentes personajes, pero que nos decantamos por la posibilidad de que se refiera a Apolo, quien, con su triunfo sobre Pitón, encarna la victoria del orden sobre el caos, de la luz sobre las tinieblas.

Este hecho mítico, que entronca con el origen de la civilización, es aprovechado por los monarcas teménidas como alegoría de su propia dominación sobre el pueblo macedonio, que se remonta a la misma formación del reino ${ }^{119}$ y que se hace evidente en el control de este ritual. La ceremonia se podía convocar también, como parecen atestiguar las palabras de Quinto Curcio Rufo, con motivo de divisiones internas que amenazan la unidad y que, según han apuntado algunos autores, podría servir también como ceremonia de incorporación de nuevos soldados a las huestes macedonias. Sea como fuere, la iniciativa reside en el monarca, que es el que encabeza el desfile con las armas y emblemas de su estirpe.

Sin embargo, para reproducir este arquetipo mítico, era necesario realizar una purificación previa, de ahí el sacrificio ritual de una perra cuya sangre impura sirve para expiar, por un principio mágico, los males de los soldados integrantes del ejército, habilitándoles para poder recrear el combate objeto del festival. Tal y como hemos visto, con la información disponible hoy en día, no podemos concluir de una forma tajante en honor de qué divinidad se producía el sacrificio, pero los indicios expuestos en este artículo hacen pensar que Enodia, el equivalente a Hécate en Tesalia y Macedonia, tuvo una presencia importante en este tipo de ceremonias, no solo vinculadas al ámbito militar, sino también civil, pues aparece como diosa tutelar de jóvenes y recién nacidos, lo que podría hablarnos de su importancia en ritos de paso o como divinidad protectora.

Dado que Enodia tuvo un gran arraigo en Tesalia, donde se han encontrado un importante número de inscripciones y un templo consagrado a ella en Feras, podemos plantear que esta tradición podría haber sido importada con los contingentes de tropas que Filipo II incorporó a su ejército al proclamarse tagos de la Liga Tesalia. El hecho de que el culto a Enodia estuviera ya presente en Macedonia, como atestiguan los altares e inscripciones hallados en las tierras altas, y que Filipo II pudiera haber conocido también los atributos de esta diosa durante su estancia en Tebas y su asistencia a los misterios de Samotracia, pudo contribuir a que su asimilación fuera más sencilla, o incluso impulsada por él mismo como elemento cohesionador.

115 Sobre Galintias puede consultarse Ovidio, Metamorfosis, 272-323.

116 Hard, 2008: 328.

117 Sobre la muerte de Heracles puede consultarse Apolodoro, II, 7-7 y Ovidio, Metamorfosis, 134-272.

118 Campbell, 2013: 241.

119 Sobre el origen del reino de Macedonia de la mano de la dinastía teménida se puede consultar Herodoto, VIII, 138; Tucídides, II, 99; Higinio, Fábulas, 219 y Diodoro Sículo, VII, 15-16. 
No tenemos que olvidar tampoco, como se ha visto, la estrecha relación entre Enodia y Artemis, que aparecen fusionadas en templos como el de Pasikrata, lo que pone de manifiesto un vínculo interesante de esta diosa con la caza, actividad de gran prestigio social entre tesalios y macedonios, como atestigua la ceremonia de la ephebeia, que marcaba la transición de la niñez a la madurez.

En el estado actual de la investigación, en espera de que la arqueología pueda deparar más información sobre los festivales macedonios, estas hipótesis quedan en el terreno de las conjeturas, pero esperamos reabrir una nueva vía de debate en relación con esta cuestión, que plantearía la posibilidad de que una diosa vinculada tradicionalmente con el mundo subterráneo, y más tarde con la hechicería, pudiera haber tenido cierto arraigo entre los soldados del ejército macedonio, en especial de los tesalios.

\section{BIBLIOGRAFÍA}

Baring, A. y Cashford, J. (2014): El mito de la diosa. Madrid, Siruela.

Baege, W. (1923, or. 1913): De Macedonum sacris. Halle, Formis Descripsit Ehrhardt Karras.

Bermejo Barrera, J. C. (2001): «Hécate y Asteria: aspectos de la concepción del espacio en la Teogonía hesiódica». Fronteras e identidad en el mundo griego antiguo. III Reunión de Historiadores del Mundo Antiguo, 2000. Universidad de Santiago de Compostela y Universidad de Vigo: 15-28.

Borza, E. N. (1990): In the shadow of Olympus. The emergence of Macedon. Princeton, Princeton University Press.

Burkert, W. (2007): Religión griega arcaica y clásica. Madrid, Abada Ediciones.

Calvo Martínez, J. L. (1992): «La diosa Hécate: un paradigma de sincretismo religioso del helenismo tardío». Florentia Iliberritana, 3: 71-82.

Campbell, J. (2013): Diosas. Gerona, Atalanta.

Carpenter, T. H. (1991): Arte y mito en la Antigua Grecia. Barcelona, Destino.

Chatzinikolaou, K. G. (2010): «Locating Sanctuaries in Upper Macedonia according to archaeological data». Kernos, 23: 193-222. http://dx.doi.org/10.4000/kernos.1580

Chevalier, J. y Gheerbrant, A. (2007): Diccionario de símbolos. Barcelona, Herder.

Chrysostomou, P. (1993-1994): «Oi thessalomakedonikoi theoi ton katharmon». Makedonika, 29: 175207.

Chrysostomou, P. (1998): I Thessaliki Thea En(n)odia i Pheraia Thea. Atenas, Tameio Archaiologikôn Poron kai Apallotriôséôn.

Chrysostomou, P. (2011): «The ancient settlement of Archontiko». The Archaeological Museum of Pella. Atenas, Latsis Foundation: 299-392.

Dubois, L. (1987): «Zeus Tritodios». Revue des Études Grecques, 100: 458-461. http://dx.doi. org/10.3406/reg.1987.1519

Eliade, M. (2008, or. 1951): El mito del eterno retorno. Madrid, Alianza.

Farnell, L. R. (1895-1909): The Cults of the Greek States. Oxford, Clarendom Press.

Frazer, J. G. (2011, or. 1922): La Rama Dorada. Madrid, Fondo de Cultura Económica.

Gimbutas, M. (2014): Diosas y dioses de la Vieja Europa (7000-3500 a. C.). Madrid, Siruela.

Goukowsky, P. (2009): Études de philologie et d'histoire ancienne: Macedonia varia. Nancy, ADRA.

Gow-Page, A.S.F. (1965): The Greek Anthology: Hellenistic Epigrams. Cambridge, University Press.

Graekos, I. (2011): «War and hunting: the world of the Macedonian King and his companions». Heracles to Alexander the Great. Oxford, Ashmolean: 75-92.

Granier, F. (1931): Die makedoniscke Heeresversammlung. Ein Beitrag zum antiken Staatsrecht. Munich, Verlag C.H. Beck.

Graninger, C. D. (2006): «The regional cults of Thessaly». Cornell Theses and Dissertations. Cornell University. https://ecommons.cornell.edu/handle/1813/2595?mode=full

Graninger, C. D. (2009): «Apollo, Ennodia, and fourth-century Thessaly». Kernos, 22: 109-124. http:// dx.doi.org/10.4000/kernos. 1775

Graninger, C. D. (2010): «Macedonia and Thessaly». A companion to Ancient Macedonia: 306-325. 
Grimal, P. (2008): Diccionario de mitología griega y romana. Barcelona, Paidós.

Hard, R. (2008): El gran libro de la mitología griega. Madrid, La Esfera de los libros.

Hadzisteliou-Price, T. (1971): «Double and multiple Representation in Greek Art and Religious Thought». The Journal of Hellenic Studies, 91: 48-69. http://dx.doi.org/10.2307/631369

Hatzopoulos, M. I. (1994): «Cultes et rites de passage en Macedoine». Meletemata, 19. Atenas, Éditions de Boccard.

Hocart, A. M. (1935): Le progrès de l'homme. París, Payot.

Kalleris, J. N. (1976): Les anciens Macédoniens, étude linguistique et historique. Atenas, Instituto Francés.

Kraus, T. (1960): Hekate: Studien zu Wsen und Bild der Göttin in Kleinasien ind Griechenland. Heidelberg, Carl Winter Universitat Verlag.

Kottaridi, A. (2013): Aigai, the royal metropolis of the macedonians. Atenas, Latsis Foundation.

Le Bohec-Bouhet, S. (2011): «Les chiens en Macédoine dans l'Antiquité». N. Badoud (éd.), Philologos Dionysios: mélanges offerts au professeur Denis Knoepfler. Genéve: 491-515.

Mastrokostas, E. (1978): «On the Grave Epigram from Pella, AAA X (1977) 259-263». Athens Annals of Archaeology, 11: 196-197.

Mazon, P. (1923): Hésiode, les travaux et les jours le bouclier. París, Les Belles Lettres.

Mazzola, E. (2006): «Ecate: solo dea delle donne?. La dea nelle testimonianzse litterarie dalle origini al III secolo a. C.». Acme, 59: 305-318.

Mili, M. (2015): Religion and Society in Ancient Thessaly. Oxford, Oxford Classical Monographs.

Molina Marín, A. I. (2015): «Tifones y gigantes en el mundo macedonio: el rey como símbolo del orden cósmico». Gerión, 33: 67-88. http://dx.doi.org/10.5209/rev_geri.2015.v33.50974

Molina Martín, C. (2014): Hécate: paradigma de la relación entre la mujer, la luna y la magia. Trabajo de fin de máster. Madrid, Universidad Complutense. http://eprints.ucm.es/28358/1/Eprints_TFM_ Celia Molina.pdf

Morgan, $\overline{\mathrm{C}}$. (2003): Early greek states beyond the polis. Londres, Routledge.

Muller, K. O. (1820): Geschichten hellenischer Stämme und Städte I. Breslau, Verlag Von Josef Mar.

Nilsson, M. (1906): Griechische Feste von religiöser Bedeutung. Leipzig, B. G. Teubner.

Nilsson, M. (1961, or. 1940): Greek folk religion. Nueva York, Columnia University Press.

Nilsson, M. (1961-1967): Geschichte der griechischen Religion. Munich, Verlag C.H. Beck.

Papachatzis, N. (1958): «Pasikrata en Demetrias». Thessalika, I: 50-65.

Philippson, P. (1944): Thesalische Mythologie. Zurich.

Ridgway, B. S. (2001): Hellenistic Sculpture, I. Wisconsin, The University of Wisconsin Press.

Robert, L. (1960): «Une deésse à cheval en Macédoine». Hellenica, 11-12: 588-595.

Ronan, S. (1992): The Goddess Hekate. Hastings, Chthonios Books.

Rudolf, I. R. von (1999): Hekate in Early Greek Religion. Victoria, Horned Owl Publishing.

Serafini, N. (2015): La dea Ecate nell'antica Grecia: una protettrice dalla quale prottegersei. Roma, Aracne.

Tarn, W. (1928): «Macedonia and Greece». The Cambridge Ancient History, VII: 197-223. Cambridge. Usener, H. (1913): Kleine Schriften IV. Cambridge, Cambridge University Press.

Wallbank, F. W. (2002): Polybius, Rome and the Hellenistic World: Essays and Reflections. Cambridge, Cambridge University Press.

Wilamowitz-Moellendorf, U. (1931): Der Glaube der Hellenen. Berlín, Weidmannsche Buchhandlug.

Recibido: 01/03/2016

Aceptado: 11/04/2016

Gladius, XXXVI (2016), pp. 59-76. ISSN: 0436-029X. doi: 10.3989/gladius.2016.0004 